\title{
Screening for Lung Cancer Using Low-dose Chest Computed Tomography in Korean Long-term Colorectal Cancer Survivors
}

ORIGINAL

ARTICLE

\author{
Ji Soo Park ${ }^{1,2}$, Beodeul Kang ${ }^{2}$, Yehyun Park ${ }^{3,4}$, Soo Jung Park ${ }^{3,4}$, Jae Hee Cheon ${ }^{3,4}$, Minkyu Jung ${ }^{2,3}$, Seung Hoon Beom ${ }^{2,3}$, \\ Sang Joon Shin ${ }^{2,3}$, Hyuk Hur ${ }^{3,5}$, Byung Soh Min ${ }^{3,5}$, Seung Hyuk Baik ${ }^{3,5}$, Kang Young Lee, ${ }^{3,5}$, Joong Bae Ahn ${ }^{2,3}$, \\ Nam Kyu Kim ${ }^{3,5}$, Tae II Kim 1,3 \\ ${ }^{1}$ Cancer Prevention Center, Yonsei Cancer Center, ${ }^{2}$ Division of Medical Oncology, Department of Internal Medicine, Yonsei University College of \\ Medicine, ${ }^{3}$ Colorectal Cancer Center, Yonsei Cancer Center, ${ }^{4}$ Division of Gastroenterology, Department of Internal Medicine, ${ }^{5}$ Department of Surgery, \\ Yonsei University College of Medicine, Seoul, Korea
}

\begin{abstract}
Background: The National Lung Screening Trial (NLST) and NELSON trial showed that low-dose chest computed tomography (LDCT) screening significantly reduced the mortality form lung cancer. Although cancer survivors are known to have high risk for second malignant neoplasm (SMN), the usefulness of LDCT screening for lung cancer in cancer survivors is not clear.

Methods: Between August 2016 and August 2017, 633 long-term colorectal cancer (CRC) survivors visited the survivorship clinic in Cancer Prevention Center, Yonsei Cancer Center, Seoul, Republic of Korea. We surveyed the smoking status and recommended LDCT screening to ever-smoking CRC survivors aged 55-80 years. The participants were classified into three risk groups: risk group 1 (RG1) who met the NLST criteria (Age 55-74 years, $\geq 30$ pack-years of smoking, smoking cessation $<15$ years); risk group 2 (RG2) who would not meet the NLST criteria but were at increased 6-year risk of lung cancer ( PLCOM2012 $_{2} \geq 0.0151$ ); risk group 3 (RG3) who did not meet any of the criteria above.

Results: Among 176 ever-smoking CRC survivors, 173 (98.3\%) were male, 32 (18.2\%) were current-smoker, and median age was 66 years (range, $55-79$ years). We found 38 positive findings (non-calcified nodule $\geq 4 \mathrm{~mm}$ ), 8 clinically significant findings, 66 minor abnormalities, and 64 negative findings on LDCT. Positive findings were identified in 15 of $79(19.0 \%)$ of RG1, in 9 of $36(25 \%)$ of RG2, and in 14 of $61(23.0 \%)$ of RG3. Second primary lung cancers were found in 2 patients of RG2, and in 1 patient of RG3. SMN was most frequently found in RG2 (11 of 36 patients, $30.6 \%$ ), compared with RG1 $(12.7 \%)$ or RG3 $(9.8 \%)(P=0.016)$.

Conclusions: LDCT screening for lung cancer in Korean CRC survivors is feasible. Well-designed clinical trial for defining high risk patients for lung cancer among CRC survivors is needed.
\end{abstract}

(J Cancer Prev 2019;24:48-53)

Key Words: Cancer survivors, Colorectal neoplasm, Second primary neoplasms, Early detection of cancer

\section{INTRODUCTION}

Colorectal cancer is the second most common cancer and the fourth leading cause of cancer death in Korea [1]. With the recent advances in cancer screening and treatment, the number of long-term colorectal cancer survivors who lived longer than 5 years from the time of diagnosis increased to 110,000 in Korea [1]. Among the cancer survivors, second malignant neoplasm (SMN) has become an important issue. National Cancer Institute's Surveillance, Epidemiology, and End Results (SEER) reported that $8 \%$ of cancer survivors developed SMN, and the risk was $14 \%$ higher compared to those in general population [2,3]. The occurrence of SMN is thought to be associated with treatmentrelated factors, lifestyle, environment, host factors, and genetics-environment [4]. In addition, because the frequency and clinical outcome of SMN is different according to the kinds of first

Received March 22, 2019, Accepted March 23, 2019

Correspondence to: Tae Il Kim

E-mail: taeilkim@yuhs.ac, ORCID: Tae Il Kim, https://orcid.org/0000-0003-4807-890X

Copyright (C) 2019 Korean Society of Cancer Prevention

(c) This is an Open Access article distributed under the terms of the Creative Commons Attribution Non-Commercial License (http://creativecommons.org/licenses/by-nc/4.0) which permits unrestricted non-commercial use, distribution, and reproduction in any medium, provided the original work is properly cited. 
primary malignancy and SMN, personalized preventive strategies are needed. For colorectal cancer survivors, lung cancer was reported to be the second common SMN following prostate cancer [3]. Considering that lung cancer was the leading cause of mortality for SMN as well as first primary malignancy [3], proper screening program for lung cancer is necessary for management of colorectal cancer survivors.

In 2011, the National Lung Screening Trial (NLST) demonstrated that annual screening program with low-dose helical computed tomography (CT) in high risk patients could reduce $20 \%$ of mortality in consequence of lung cancer. Although several problems were proposed including overdiagnosis, cost-effectiveness, and long-term follow-up schedule, low-dose CT screening is currently recommended by the experts in many guidelines for the population with high risk for lung cancer [5-9]. In Korea, low-dose CT screening is recommended for the patients with high risk for lung cancer, and will be included in the national cancer screening program before the end of the year [10].

In this study, we conducted the lung cancer screening using low-dose chest CT in long-term colorectal cancer survivors with smoking history. We also tried to find the feasibility of low-dose CT screening in terms of lung-cancer risk groups, radiologic findings, and clinical outcome in the colorectal cancer survivors.

\section{MATERIALS AND METHODS}

\section{Study population and definition}

Between August 2016 and August 2017, we enrolled colorectal cancer survivors for long-term survivorship management in Cancer Prevention Center, Yonsei Cancer Center, Seoul, Republic of Korea. The eligibility criteria were as below: men and women aged 55 to 80 years of age; ever-smoker; histologically diagnosed colorectal cancer; survival more than 4 years from diagnosis of cancer; without evidence of known history of lung cancer and/or pulmonary metastases. The information about smoking was collected using verbal surveys: (1) smoking status; (2) smoking intensity; (3) smoking duration; (4) If the subject was a former smoker, duration of smoking cessation. Ever-smoker was defined as a subject who smoked at least 100 cigarettes in the lifetime. If the participant smoked cigarettes currently or during the last 30 days, he or she was classified into a current smoker. Smoking intensity was defined as an average number of cigarettes smoked a day. If the patients expressed the number of cigarettes by pack, 20 cigarettes were considered as a pack. Pack-years was calculated by multiplying smoking intensity in pack by smoking duration in year. Clinical characteristics were collected using electronic medical record. This study was approved by Institutional Review Board at Severance Hospital, Seoul, Korea (IRB approval number 4-2016-0522).

\section{Radiologic and clinical outcome measurement}

We recommended the ever-smoking colorectal cancer survivors to receive low-dose chest CT screening for lung cancer. For the patient who agreed to the lung cancer screening, low-dose CT was performed on multidetector helical CT scanners of four channels. On the low-dose CT images, noncalcified nodules with long-axis diameters of $4 \mathrm{~mm}$ or greater in the axial plane, adenopathy, or effusion were classified as positive, which were suspicious for lung cancer. Other clinically significant condition other than lung cancer and minor abnormality was also recorded [11]. Subsequent assessment or management followed general clinical practice. As of February 2019, recurrence of primary malignancy or occurrence of SMN were reviewed using medical records.

\section{Lung cancer risk assessment}

Six-year risk of lung cancer was calculated using the modified lung-cancer risk-prediction model from Prostate, Lung, Colorectal, and Ovarian (PLCO) Cancer Screening model $\left(\mathrm{PLCO}_{\mathrm{M} 2012}\right)$ [12]. The participants were classified into three risk groups using the NLST criteria and a 6-year risk-prediction model ( $\left.\mathrm{PLCO}_{\mathrm{M} 2012}\right)$ : (1) risk group 1, current smokers or former smokers within the previous 15 years, aged 55 to 74 years, and with a history of at least 30 pack-years of cigarette smoking; (2) risk group 2, except the subject who met the criteria of risk group 1 , current or former smokers, with a history of at least 20 pack-years of cigarette smoking and a 6-year risk of lung cancer $\geq 0.0151$ [13]; (3) risk group 3, other patients who did not meet the criteria of risk group 1 nor risk group 2.

\section{Statistical analyses}

The differences of clinicopathologic variables, cancer-related factors were analyzed using Pearson's $\chi^{2}$ test, Mann-Whitney U-test, Kruskal-Wallis test, and Fisher's exact test according to the lung-cancer risk groups. $P$-value $<0.05$ was considered statistically significant. All statistical analyses were performed using IBM SPSS ver. 23 for windows (IBM Corp., Armonk, NY, USA). 


\section{RESULTS}

\section{Patients characteristics}

Between August 2016 and August 2017, 633 long-term colorectal cancer survivors visited the survivorship clinic in Cancer Prevention Center, Yonsei Cancer Center, Seoul, Republic of Korea. Forty-four patients (7.0\%) were current smokers, and 238 patients (37.6\%) were former smokers. Among 210 patients who met the eligibility criteria, 34 patients refused to receive low-dose chest CT screening for lung cancer. Therefore, 176 patients were finally enrolled in this study. Table 1 showed the baseline characteristics of the patients. Median survival time from diagnosis of cancer was 63.1 months (range, 50.5-417.2 months). One hundred seventy-three patients (98.3\%) were male, and median age was 66 years (range, 55-79 years).

\section{Risk classification according to National Lung Screening Trial criteria and PLCO $_{\mathrm{M} 2012}$ model}

All patients were classified into three risk groups using NLST criteria and 6-year risk of lung cancer ( $\left.\mathrm{PLCO}_{\mathrm{M} 2012}\right)$. Risk group 1 included the individuals with the clinical features similar to NLST criteria $(n=79)$. Risk group 2 released the age limit and selected the individuals with higher 6-year risk of lung cancer by $\mathrm{PLCO}_{\mathrm{M} 2012} \geq 0.0151$ ( $\mathrm{n}=36$ ). Risk group 3 was aimed at the individuals without significant risk factors, which meant moderate to low risk group $(n=61)$.

Although most clinical features were not different among the risk groups (Supplementary Table 1), median age was higher in risk group 2 due to the age limit (55-74 years of age) of NLST cohort in risk group 1. Current smokers accounted for $24.1 \%$, $19.4 \%$, and $9.8 \%$ of risk group 1, risk group 2, and risk group 3 , respectively. Median $\mathrm{PLCO}_{\mathrm{M} 2012}$ risk score was 0.01655 (range, $0.00009-0.21732$ ) in all patients, 0.02570 (range, 0.00651-0.21732) in risk group 1, 0.02898 (range, 0.01561-0.18717) in risk group 2, and 0.00771 (range, 0.00009-0.01534) in risk group $3(P<0.001)$.

\section{Positive radiologic findings and second malignant neoplasm}

We found 38 positive findings (non-calcified nodule $\geq 4 \mathrm{~mm}$ ), 8 clinically significant findings, 66 minor abnormalities, and 64 negative findings on low-dose chest CT (Table 2). Positive findings were identified in 15 of 79 (19.0\%) of risk group 1, in 9 of 36 (25.0\%) of risk group 2, and in 14 of 61 (23.0\%) of risk group 3, with presentation of median $6 \mathrm{~mm}$ (range, 4.3-14.0 mm) sized non-calcified nodules. Among 38 patients with positive findings, further assessment revealed 3 cases of second primary lung cancer, and 1 case of pulmonary metastasis. Second primary lung cancers were found in 2 patients of risk group 2, and in 1 patient of risk group 3. Surgical specimen of two patients showed histology of adenocarcinoma, and one patient was diagnosed with small cell lung carcinoma. One patient with pulmonary

Table 1. Baseline characteristics $(n=176)$

\begin{tabular}{|c|c|c|}
\hline Variable & & Value \\
\hline \multicolumn{3}{|l|}{ Clinical/social factors } \\
\hline \multicolumn{3}{|l|}{ Sex } \\
\hline Male & 173 & $(98.3)$ \\
\hline Female & 3 & $(1.7)$ \\
\hline Age (yr) & 66 & $(55-79)$ \\
\hline BMI $\left(\mathrm{kg} / \mathrm{m}^{2}\right)$ & 23.8 & $(16.1-34.7)$ \\
\hline \multicolumn{3}{|l|}{ Smoking status } \\
\hline Current & 32 & $(18.2)$ \\
\hline Former & 144 & $(81.8)$ \\
\hline Smoking intensity (cigarette) & 20 & $(3-60)$ \\
\hline Smoking duration (yr) & 30 & $(6-60)$ \\
\hline Pack-years & 30 & $(5-135)$ \\
\hline Duration of smoking cessation (yr) & 9 & $(0-42)$ \\
\hline \multicolumn{3}{|l|}{ Hypertension } \\
\hline Yes & 65 & $(36.9)$ \\
\hline No & 111 & $(63.1)$ \\
\hline \multicolumn{3}{|l|}{ Diabetes mellitus } \\
\hline Yes & 44 & $(25.0)$ \\
\hline No & 132 & $(75.0)$ \\
\hline \multicolumn{3}{|l|}{ COPD } \\
\hline Yes & 33 & $(18.8)$ \\
\hline No & 143 & $(81.3)$ \\
\hline \multicolumn{3}{|l|}{ Education status } \\
\hline Less than high school graduate & 42 & $(23.9)$ \\
\hline High school graduate & 71 & $(40.3)$ \\
\hline College graduate or higher & 63 & $(35.8)$ \\
\hline \multicolumn{3}{|l|}{ Colorectal cancer-related factors } \\
\hline \multicolumn{3}{|l|}{ Location } \\
\hline Right-sided & 30 & $(17.0)$ \\
\hline Left-sided & 146 & $(83.0)$ \\
\hline \multicolumn{3}{|l|}{ Histological differentiation } \\
\hline Adenocarcinoma, well differentiated & 32 & $(18.2)$ \\
\hline Adenocarcinoma, moderately differentiated & 130 & $(73.9)$ \\
\hline Adenocarcinoma, poorly differentiated & 6 & $(3.4)$ \\
\hline Mucinous carcinoma & 3 & $(1.7)$ \\
\hline Others & 5 & $(2.8)$ \\
\hline \multicolumn{3}{|l|}{ Stage } \\
\hline 0 & 1 & $(0.6)$ \\
\hline I & 38 & $(21.6)$ \\
\hline II & 51 & $(29.0)$ \\
\hline III & 77 & $(43.8)$ \\
\hline IV & 9 & $(5.1)$ \\
\hline \multicolumn{3}{|l|}{ Adjuvant chemotherapy } \\
\hline Yes & 123 & $(69.9)$ \\
\hline No & 53 & $(30.1)$ \\
\hline
\end{tabular}

Values are presented as number (\%) or median (range). BMI, body mass index; COPD, chronic obstructive pulmonary disease. 
Table 2. Result of low-dose chest computed tomography screening according to the risk groups $(n=176)$

\begin{tabular}{lrrr}
\hline Variable & Positive results & $\begin{array}{c}\text { Clinically significant abnormality } \\
\text { not suspicious for lung cancer }\end{array}$ & No or minor abnormality \\
\hline Risk group 1 & $15(19.0)$ & $4(5.1)$ & $60(75.9)$ \\
Risk group 2 & $9(25.0)$ & $2(5.6)$ & $25(69.4)$ \\
Risk group 3 & $14(23.0)$ & $2(3.2)$ & $45(73.8)$ \\
Total & $38(21.6)$ & $8(4.5)$ & $130(73.9)$ \\
\hline
\end{tabular}

Values are presented as number (\%). ${ }^{\text {a}}$ Risk group 1 includes the individuals who meet the criteria of National Lung Screening Trial (NLST):

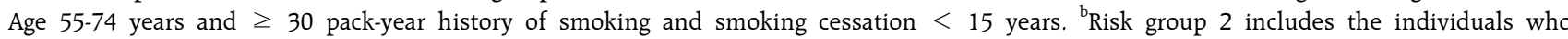
would not meet the NLST criteria but are possibly related to the similar risk to those of NLST cohort: Age 50 years and $\geq 20$ pack-year history of smoking and additional risk factors that increase the 6-year risk of lung cancer (PLCO ${ }_{\text {M2012 }}$ [Prostate, Lung, Colorectal, and Ovarian Cancer Screening model] $\geq 0.0151)$. 'Risk group 3 includes the individuals without risk factors, classified as moderate to low risk group.

Table 3. Occurrence of second malignant neoplasm (SMN) according to the risk groups $(\mathrm{n}=176)$

\begin{tabular}{|c|c|c|c|c|}
\hline Kind of SMN & Risk group $1^{\mathrm{a}}(\mathrm{n}=79)$ & Risk group $2^{\mathrm{b}}(\mathrm{n}=36)$ & Risk group $3^{c}(n=61)$ & $P$-value \\
\hline Colon & $0(0)$ & $2(5.6)$ & $3(4.9)$ & $0.086^{\mathrm{d}}$ \\
\hline Stomach & $4(5.1)$ & $4(11.1)$ & $0(0)$ & $0.024^{\mathrm{d}}$ \\
\hline Kidney & $2(2.5)$ & $1(2.8)$ & $1(1.6)$ & $>0.99^{\mathrm{d}}$ \\
\hline Prostate & $1(1.3)$ & $2(5.6)$ & $1(1.6)$ & $0.419^{\mathrm{d}}$ \\
\hline Lung & $0(0)$ & $2(5.6)$ & $1(1.6)$ & $0.091^{\mathrm{d}}$ \\
\hline Thyroid & $2(2.5)$ & $0(0)$ & $0(0)$ & $0.687^{\mathrm{d}}$ \\
\hline Esophagus & $0(0)$ & $1(2.8)$ & $0(0)$ & $0.205^{\mathrm{d}}$ \\
\hline Head and Neck & $1(1.3)$ & $0(0)$ & $0(0)$ & $>0.99$ \\
\hline Hepatobiliary & $0(0)$ & $0(0)$ & $1(1.6)$ & $0.551^{\mathrm{d}}$ \\
\hline Hematology & $1(1.3)$ & $0(0)$ & $1(1.6)$ & $>0.99$ \\
\hline Any kind of SMN & $10(12.7)$ & $11(30.6)$ & $6(9.8)$ & 0.016 \\
\hline
\end{tabular}

Values are presented as number (\%). ${ }^{a}$ Risk group 1 includes the individuals who meet the criteria of National Lung Screening Trial (NLST): Age 55-74 years and $\geq 30$ pack-year history of smoking and smoking cessation $<15$ years. ${ }^{\text {bisk }}$ group 2 includes the individuals who would not meet the NLST criteria but are possibly related to the similar risk to those of NLST cohort: Age 50 years and $\geq 20$ pack-year history of smoking and additional risk factors that increase the 6-year risk of lung cancer (PLCO M2012 $_{\text {[Prostate, Lung, Colorectal, and Ovarian }}$ Cancer Screening model] $\geq 0.0151)$. 'Risk group 3 includes the individuals without risk factors, classified as moderate to low risk group. ${ }^{\mathrm{d}}$ These values were analyzed using Fisher's exact tests.

metastasis had the clinical features of risk group 2. In addition, among 176 colorectal cancer survivors, 27 patients were diagnosed with any kind of SMN. Common SMNs were colon, stomach, kidney, prostate, and lung cancer. In terms of risk groups, SMN was most frequently found in risk group 2 (11 of 36 patients, 30.6\%), compared with risk group 1 (12.7\%) or risk group $3(9.8 \%)(P=0.016)$ (Table 3).

\section{DISCUSSION}

Overall risk of SMN is approximately $8.1 \%$ for the common cancer survivors [3], and lung cancer is one of the most common SMNs. In terms of the risk of lung cancer, prior diagnosis of malignant tumor was considered as an independent risk factor in the lung-cancer prediction models including the Liverpool Lung Project risk model [14] and $\mathrm{PLCO}_{\mathrm{M} 2012}$ model [12]. However, adequate method for lung cancer screening in other cancer survivors was not well established. In this study, we conducted lung cancer screening with low-dose chest CT for colorectal cancer survivors with a smoking history. We also attempted to find the feasibility of low-dose chest CT screening by analyzing the radiologic findings, risk stratification, and clinical outcomes.

In addition to the favorable result of NLST which changed the standard of lung cancer screening methods for high-risk individuals [11], recently updated result of NELSON trial also presented that low-dose CT screening decreased mortality by $26 \%$ in men and up to $61 \%$ in women with high risk at 10 years [15]. With the progress of low-dose chest CT screening in clinical practice, several issues surrounding cost-effectiveness [16] and overdiagnosis [17] were frequently discussed. To avoid excessive CT scan to low-risk individuals, researchers tried to increase interval between the screens in the patients with a negative TO 
(prevalence) screen [18], or apply a personalized screening methods according to the risk of lung cancer mortality [19].

Meanwhile, NLST cohort defined the high-risk individuals as men or women aged 55 to 74 years with at least a 30 pack-year history of cigarette smoking, and, if a former smoker, had quit within the past 15 years, and this definition is similarly used in many clinical guidelines [5,7-9]. The American Association for Thoracic Surgery (AATS) guideline recommended to continue screening to age 79 years because of the peak incidence of lung cancer (70 years in the United States) and prolonged life expectancy. AATS included the individuals aged $\geq 50$ years, $\geq 20$ pack-year smoking, and $\geq 5 \%$ risk of developing lung cancer within 5 years to their screening criteria [9]. The NCCN guideline similarly provides additional criteria for the individuals with high risk of lung cancer other than cumulative dose of smoking and duration of smoking cessation [5]. The PLCO predictive model was designed using data collected in the PLCO Cancer Screening Trial for ever-smokers [20], and revised to ensure applicability to NLST data $\left(\mathrm{PLCO}_{\mathrm{M} 2012}\right)$ [12]. $\mathrm{PLCO}_{\mathrm{M} 2012}$ criteria were known to have improved sensitivity $(83.0 \%)$ and positive predictive value (4.0\%) compared to NLST criteria [12]. According to the guidelines from ATTS and NCCN, we would consider to screen the patients older than 74 years of age, and former smoker who stopped smoking more than 15 years ago, but with high risk score (i.e., 6-year risk in $\mathrm{PLCO}_{\mathrm{M} 2012} \geq 0$ 0.0151) [13].

In the present study, the proportion of positive result was $21.6 \%$, and only 3 of which (7.8\% of total positive tests) was proved to be primary lung cancers. Considering the proportion of positive result was $27.3 \%$ and the proportion of confirmed lung cancer was $3.8 \%$ in T0 round of low-dose CT arm in the NLST [11], our results were consistent to those of previous study. However, among the participants in risk group 1, who met the criteria of NLST, the proportions of positive results and confirmed lung cancer were $19.0 \%$ and $0 \%$, respectively. Instead, 2 lung cancers were found in risk group 2, and 1 lung cancer was found in risk group 3; Patient\#1 was 76-year-old male and current smoker with a 54 pack-year history of smoking. Because of the old age ( $\geq 75$ years of age), he was classified into risk group 2 . He was diagnosed with small cell lung cancer, and his 6-year risk ( $\left.\mathrm{PLCO}_{\mathrm{M} 2012}\right)$ was 0.13920 . Patient\# 2 was 78 -year-old male and former smoker with a 100 pack-year history of smoking and 7 years of smoking cessation. He was classified into risk group 2 with 6-year risk $\left(\mathrm{PLCO}_{\mathrm{M} 2012}\right)$ of 0.11314 . He was diagnosed with non-small cell lung cancer (adenocarcinoma). Patient\#3 was 73-year-old male and former smoker with a 15 pack-year history of smoking and 16 years of smoking cessation. He was classified into risk group 3 with 6-year $\mathrm{PLCO}_{\mathrm{M} 2012}$ value of 0.01178 . He was diagnosed with adenocarcinoma in situ (AIS).

Although the personal history of malignant tumor increases the possibility of lung cancer [12,14], the efficacy of lung cancer screening is not fully investigated in cancer survivors. Because most prospective large-scale clinical trials excluded the participation of other cancer survivors, clinical outcome of screening program in cancer survivors had generally been estimated in real-world practice [21]. Despite its small sample size, this study has clinical meaning to apply the low-dose chest CT screening to colorectal cancer survivors, and to analyze the clinical outcome with risk groups using NLST criteria and well-designed lung-cancer risk prediction model ( $\mathrm{PLCO}_{\mathrm{M} 2012}$ ). Among 176 ever-smoker colorectal cancer survivors, we found 3 patients with second primary lung cancer. However, two of the patients did not meet NLST criteria, but had high $\mathrm{PLCO}_{\mathrm{M} 2012}$ score with age older than 74 years. Moreover, another one patient with AIS even had low $\mathrm{PLCO}_{\mathrm{M} 2012}$ prediction score. In Korea, in common with United States documented in AATS guidelines, the peak age of incidence of lung cancer was 70 years, and average life expectancy was 79 years of age in men and 85 years of age in women [22]. Therefore, we carefully suggest that lung cancer screening could be considered in the patients aged 75-80 years with good performance but high risk for lung cancer. Further, we need to develop a novel lung-cancer risk prediction model reflecting the different epidemiology of lung cancer in Asia.

Low-dose chest CT screening for lung cancer is feasible as a screening method for SMN in Korean colorectal cancer survivors. However, the screening criteria should be more enhanced and personalized. Well-designed clinical trials using personalized cancer risk-prediction tools are needed for cancer survivors.

\section{ACKNOWLEDGMENTS}

This study was supported by a grant from the National R\&D Program for Cancer Control, Ministry of Health \& Welfare, Republic of Korea (1631020).

\section{CONFLICTS OF INTEREST}

No potential conflicts of interest were disclosed.

\section{Supplementary Materials}

Supplementary materials can be found via https://doi.org/ 10.15430/JCP.2019.24.1.48. 


\section{REFERENCES}

1. Jung KW, Won YJ, Kong HJ, Lee ES; Community of PopulationBased Regional Cancer Registries. Cancer statistics in Korea: incidence, mortality, survival, and prevalence in 2015. Cancer Res Treat 2018:50:303-16.

2. Curtis RE, Freedman DM, Ron E, Ries LAG, Hacker DG, Edwards BK, et al. New malignancies among cancer survivors: Seer cancer registries, 1973-2000. Bethesda, National Cancer Institute, 2006.

3. Donin N, Filson C, Drakaki A, Tan HJ, Castillo A, Kwan L, et al. Risk of second primary malignancies among cancer survivors in the United States, 1992 through 2008. Cancer 2016;122:3075-86.

4. Travis LB, Rabkin CS, Brown LM, Allan JM, Alter BP, Ambrosone $\mathrm{CB}$, et al. Cancer survivorship-genetic susceptibility and second primary cancers: research strategies and recommendations. J Natl Cancer Inst 2006;98:15-25.

5. National Comprehensive Cancer Network. NCCN clinical practice guidelines in oncology: lung cancer screening version 2. https:// www.nccn.org/professionals/physician_gls/pdf/lung_screening. pdf. Accessed on March 21, 2019.

6. Wender R, Fontham ET, Barrera E Jr, Colditz GA, Church TR, Ettinger DS, et al. American Cancer Society lung cancer screening guidelines. J Natl Cancer Inst 2013;63:107-17.

7. Moyer VA. Screening for lung cancer: U.S. Preventive Services Task Force recommendation statement. Ann Intern Med 2014; 160:330-8.

8. Detterbeck FC, Mazzone PJ, Naidich DP, Bach PB. Screening for lung cancer: diagnosis and management of lung cancer, 3rd ed: American College of Chest Physicians evidence-based clinical practice guidelines. Chest 2013;143:e78S-92S.

9. Jaklitsch MT, Jacobson FL, Austin JH, Field JK, Jett JR, Keshavjee $\mathrm{S}$, et al. The American Association for Thoracic Surgery guidelines for lung cancer screening using low-dose computed tomography scans for lung cancer survivors and other high-risk groups. J Thorac Cardiovasc Surg 2012;144:33-8.

10. Jang SH, Sheen SS, Kim HY, Yim HW, Kim JW, Park IG, et al. The Korean guideline for lung cancer screeningung cancer screening. J Korean Med Assoc 2015;58:291-301.

11. National Lung Screening Trial Research Team, Aberle DR, Adams AM, Berg CD, Black WC, Clapp JD, et al. Reduced lung-cancer mortality with low-dose computed tomographic screening. $\mathrm{N}$ Engl J Med 2011;365:395-409.

12. Tammemägi MC, Katki HA, Hocking WG, Church TR, Caporaso N, Kvale PA, et al. Selection criteria for lung-cancer screening. N Engl J Med 2013;368:728-36.

13. Tammemägi MC, Church TR, Hocking WG, Silvestri GA, Kvale PA, Riley TL, et al. Evaluation of the lung cancer risks at which to screen ever- and never-smokers: screening rules applied to the PLCO and NLST cohorts. PLoS Med 2014;11:e1001764.

14. Cassidy A, Myles JP, van Tongeren M, Page RD, Liloglou T, Duffy SW, et al. The LLP risk model: an individual risk prediction model for lung cancer. Br J Cancer 2008;98:270-6.

15. De Koning H, Van Der Aalst C, Ten Haaf K, Oudkerk M. Effects of volume CT lung cancer screening: mortality results of the NELSON randomised-controlled population based trial. J Thorac Oncol 2018;13:S185.

16. Black WC, Gareen IF, Soneji SS, Sicks JD, Keeler EB, Aberle DR, et al. Cost-effectiveness of $\mathrm{CT}$ screening in the National Lung Screening Trial. N Engl J Med 2014;371:1793-802.

17. Patz EF Jr, Pinsky P, Gatsonis C, Sicks JD, Kramer BS, Tammemägi $\mathrm{MC}$, et al. Overdiagnosis in low-dose computed tomography screening for lung cancer. JAMA Intern Med 2014;174:269-74.

18. Patz EF Jr, Greco E, Gatsonis C, Pinsky P, Kramer BS, Aberle DR. Lung cancer incidence and mortality in National Lung Screening Trial participants who underwent low-dose CT prevalence screening: a retrospective cohort analysis of a randomised, multicentre, diagnostic screening trial. Lancet Oncol 2016;17:590-9.

19. Kovalchik SA, Tammemagi M, Berg CD, Caporaso NE, Riley TL, Korch $\mathrm{M}$, et al. Targeting of low-dose CT screening according to the risk of lung-cancer death. N N Engl J Med 2013;369:245-54.

20. Tammemagi CM, Pinsky PF, Caporaso NE, Kvale PA, Hocking WG, Church TR, et al. Lung cancer risk prediction: prostate, lung, colorectal and ovarian cancer screening trial models and validation J Natl Cancer Inst 2011;103:1058-68.

21. Erkmen CP, Kaiser LR, Ehret AL. Lung cancer screening: should we be excluding people with previous malignancy? World J Respirol 2016;6:1-13.

22. Choi CM, Kim HC, Jung CY, Cho DG, Jeon JH, Lee JE, et al. Report of the Korean Association of Lung Cancer Registry (KALC-R), 2014 [published online ahead of print February 25, 2019]. Cancer Res Treat. doi: 10.4143/crt.2018.704. 